\title{
Mechanical Characteristics of Heat-treated Medium Carbon Steel Quenched using Blending Different Types of Vegetable Oils
}

\author{
Tajudeen Kolawole Ajiboye and Adam Olalekan Abdulsalam
}

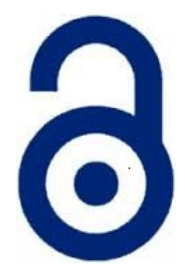

Received: 20 September 2019

Accepted: 20 November 2019

Published: 15 December 2019

Publisher: Deer Hill Publications

(c) 2019 The Author(s)

Creative Commons: CC BY 4.0

\begin{abstract}
Quenching and tempering are processes that strengthen and harden materials like steel and other iron-based alloys. Conventional heat treatment procedures for producing martensitic steels generally involve continuous and rapid cooling of an austenitized specimen in some types of quenching media such as water, oil, or air, in which the properties of steel quenched depends largely on the properties of these quenching media. Four vegetable oils: Cotton seed oil, Neem seed oil, Shea butter oil and Palm kernel oil, were blended into two different samples, namely Blend A: Cotton seed oil and Neem seed oil and Blend B: Cotton seed oil, Neem seed oil, Palm kernel oil and Shear butter oil. These were mixed in different ratios. Samples of Medium Carbon Steel were heated to $850^{\circ} \mathrm{C}$ and soaked for 10 minutes inside a Muffle Furnace before quenching in the prepared quenching media. The Microstructure and mechanical properties of the samples were investigated to determine the quenching performance of the Vegetable Oil Blends. The results showed that Blend A1 produced best properties for the Impact Strength and Yield Strength with values of $0.82 \mathrm{~J} / \mathrm{mm}^{2}$ and $429.71 \mathrm{~N} / \mathrm{mm}^{2}$ respectively. On the other hands, Blend A2 quenched Steel had best properties for the Hardness and Tensile Strength with $52.8 \mathrm{HRA}$ and $892 \mathrm{~N} / \mathrm{mm}^{2}$ respectively. Microstructure analysis also confirms improved hardness and toughness exhibiting more martensite for blend containing the four oils than blend with only two oils.
\end{abstract}

Keywords: Blend, Martensite, Quenchants, Medium Carbon Steel

\section{INTRODUCTION}

Quenching operation belongs to the processes of heat treatment, for which the highly intensive and dynamic heat transfer at the surface of the body occurs. Determination of the temperature field in the cooled body requires unity conditions of the heat conduction equation. Comparisons of different quenchants in heat treatment processes of steels are of great importance in order to achieve desired hardness, strength or toughness and minimizing the possibility of occurrence of quench cracks due to evolution of residual stresses (Totten, Howes and Maurice, 1997). The choice of effective quenching medium after heat treatment is very critical in ensuring the achievement of desired mechanical properties; hence, selection of a quenchant depends on the quench sensitivity of a particular grade of steel and the severity of quench medium (Buczek and Telejko, 2004, Feng and Tahir, 2008). Three stages of quenching are vapour blanket, in which vapour film surrounding the component acts as an insulating blanket reducing the heat flow from component subjected to quenching. The second stage is known as the nucleate boiling stage where the vapour film formed collapses and high heat extraction rates are achieved. The third stage known as convective cooling stage begins when the temperature of the metal surface is reduced below the boiling point of the quenching liquid; cooling rate is low during this stage (Buczek and Telejko, 2004, Gorysushin et al, 1991).

There are several factors influencing the effectiveness of a quenching medium in its ability to withdraw heat from a quenched part. These factors include: temperature of the medium, degree of agitation, surface conditions of the part and the type of quenching medium (Feng and Tahir, 2008, Boyer, 1984). In addition, the configuration of the quenched part also plays a role in the rate of heat transfer during quenching. The temperature of the medium has a drastic effect on its ability to extract heat from a hot part, hence lowering the bath temperature increases the heat transfer rate (Totten, Bates and Clinton, 1993George and Scott, 2003). The heat extraction is still dependent on the

T. K. Ajiboye $\square$ and A. O. Abduslam

Department of Mechanical Engineering

Faculty of Engineering and Technology

University of llorin, Ilorin, Nigeria

E-mail: ajitek@unilorin.edu.ng

Reference: Ajiboye, T. K. and Abdulsalam, A. O. (2019). Mechanical Characteristics of Heat-Treated Medium Carbon Steel Quenched using Blending different types of Vegetable Oils. International Journal of Engineering Materials and Manufacture, 4(4), 146-153. 
characteristics of the medium itself. In general, higher quenchant temperatures lower the temperature at which a total vapour blanket is maintained in the medium. As a result, it will lengthen the duration of the first stage of quenching, which lengthens the time at which the part is cooled at slower cooling rates (Mills, 1999, Incropera and DeWitt, 1996). Depending on the medium itself, higher bath temperatures may decrease viscosity, which affects bubble size and therefore, decrease the rate of heat transfer during the third stage of quenching. In the case of water, since it produces the fastest cooling rates, lower temperatures produce high thermal gradients between the bath and the part (Feng and Tahir, 2008, Boyer, 1984). As a result, high thermal stresses will be induced and the risk of distortion or cracking will increase. On the other hand, as the temperature of the water is increased to avoid cracking, the physical properties of the material decrease due to incomplete saturation of the solution during quenching (Chaves, 2001, Bell and Staines, 1983, Joseph et al (2016) and Singh, V. (2012).

Agitation plays a vital role in the effectiveness of a particular medium to quench a part, and is one of the factor that determines the success of the quenched products (Chaves, 2001). In general, agitation increases the rate of heat transfer throughout the quenching process. During the Vapour Blanket Stage, agitations will breakdown the blanket much earlier in the quench and force the Boiling Stage to begin. As a result, a stage of slow cooling is cut short and replaced with a stage of rapid heat transfer. Overall, the part will be cooled at a faster rate. In addition, it will also produce smaller, more frequent bubbles during the Boiling Stage, which, in turn, creates faster rates of heat transfer throughout the part (Adeyemi and Adedayo, 2009 and Simencio-Otero et al (2017).

In terms of its mechanical effects, any solids that have formed on the test piece will be agitated off of the surface and allow for maximum heat transfer since the medium will be in direct contact with the exposed surface. These gels would have acted as an insulating layer to slow down the cooling rate, but with the use of agitation, this layer is mechanically removed and maximum heat transfer can be achieved. Finally, agitation forces cool liquid to constantly be circulated to the work piece in place of the hot liquid (Feng and Tahir, 2008, Boyer, 1984). Therefore, higher temperature differences will always exist between the medium and the surface, resulting in faster rates of heat dissipation (Incropera and DeWitt, 1996). Lowest cooling rates are observed on surfaces that are newly machined or bright etched, whereas faster rates are obtained by surfaces with oxide films and stains. In addition, surface roughness has a similar relationship regarding cooling rates; the rougher the surface, the faster the cooling rate (Fernandes and Prabhu, 2008). This phenomenon can be attributed to the stability of the vapour phase on each surface. If the surface is smooth, then the vapour layer becomes uniform and stable, whereas if there are discontinuities on the surface, then it becomes easier to break down the layer and induce the Boiling Stage (Incropera and DeWitt, 1996). Furthermore, the application of non-reflective coatings will increase heating and affect the quench of the material (Kobasko, Canale and Totten, 2010, Odusote, Ajiboye and Abdulkarim, 2012 and Pranesh Rao, K.M. and Prabhu, K.N. (2015).

\section{MATERIAL AND METHOD \\ 2.1 Specimen's Preparation}

The Medium Carbon Steel was cut into eight (8) pieces of equal length, $65 \mathrm{~mm}$ length by $14 \mathrm{~mm}$ diameter. Four (4) of the samples were machined to $60 \mathrm{~mm}$ length by $12.5 \mathrm{~mm}$ diameter for hardness and impact test while the remaining four (4) were machined to a total length of $37.4 \mathrm{~mm}$, gauge length of $24.3 \mathrm{~mm}$, Bigger diameter (D) $7.8 \mathrm{~mm}$ and smaller diameter (d) $4.9 \mathrm{~mm}$ for tensile test. These specimens were heat-treated and quenched before the required tests were carried out. Before commencing the experiment, the chemical composition of the Medium Carbon Steel was carried out as detailed in Table 1. The four vegetable oil, (Cotton seed oil, Neem seed oil, Shea butter oil and Palm kernel oil) were sourced from local market in Niger and Katsina States, Nigeria. They were blend into 2 different samples; A and B. After the mixing of the blends, the following physical properties test were carried out on each of the blended oil products for further analysis and for necessary comparison with the available quenchants.

Blend A: This contains Cotton seed oil and Neem seed oil mixed in equal volume.

Blend B: This contains Cotton seed oil, Neem seed oil, Palm kernel oil and Shear butter oil mixed in equal volume.

\subsection{Viscosity Test}

The blended oil was put at the edge of the capillary tube and then allow to drawn to the lower and upper meniscus. When the oil reaches the upper meniscus, it was then allowed to drop under and the time taken for the oil to move from the upper meniscus to the lower meniscus was recorded. The process was also carried out for water at $25^{\circ} \mathrm{C}$. The time taken for the water was used as a reference to obtain the viscosity of the blended oil. The process was repeated four times for each of the blended samples to obtain and average value.

Table 1: Chemical composition of the Medium Carbon Steel 


\subsection{Acidic Value}

The mixture of ethanol and toluene in ratio 1:1 by volume was first neutralized prior to use by the application of ethanolic potassium hydroxide solution in the presence of $0.3 \mathrm{ml}$ of indicator per $10 \mathrm{ml}$ of the mixture. $2 \mathrm{~g}$ of the oil blend was weighed into a $250 \mathrm{ml}$ conical flask, $50 \mathrm{ml}$ of previously neutralized mixture of toluene and ethanol was added to the flask. A few drop of phenolphalein indicator was added and the content was titrated against $0.1 \mathrm{ml} /$ litre solution of ethanolic potassium hydroxide solution until the indicator changes to pink colour. The procedure was repeated for the second blended oil.

\section{4 lodine Value}

One gram (1 g) of the oil blend was weighed into a conical flask. $10 \mathrm{ml}$ of chloroform and $12 \mathrm{ml}$ of dams reagent was added to the flask. Stopper was then inserted and the content of the flask was vigorously swirled. The flask was then placed in the dark for 1 hour 30 minutes after which $10 \mathrm{ml}$ of potassium iodide solution and $750 \mathrm{ml}$ of water were added. The contents of each flask was titrated with $0.1 \mathrm{~mol} / 1$ sodium thiosulphate solution until the yellow colour due to iodine has almost disappeared. Few drops of starch were then added and titration continued until the blue colour disappeared after vigorous shaking. The process was repeated for the other blend.

\subsection{Heat Treatments and Quenching Procedure}

All the eight medium carbon steel samples which were readily prepared for the various test were loaded into a muffle furnace shown in Figure 1 and heated to a temperature of $850^{\circ} \mathrm{C}$. After attaining this temperature, they were allowed to soak for 13 minutes based on the specimen dimension. It was then quenched in the prepared quenching media.

\section{MECHANICAL PROPERTIES TEST}

\subsection{Tensile Test}

Tensile tests were conducted at various strain rates of $200,500,1000,1500$ and $1750 \mathrm{~mm} / \mathrm{min}$ for all the specimens (Ndaliman, 2006). Each of the specimens was inserted one after another into the machine jaws and having fastened the specimen properly at both ends for tensile test. The arrangement and the specimen are shown in Figure 2 and Figure 3 respectively. The machine recorded the stress, strain, elongation, yield strength and ultimate tensile strength which were printed for further analysis (Smith and Hashemi, 2006, Thomas, Samuel and Glenn, 1996).

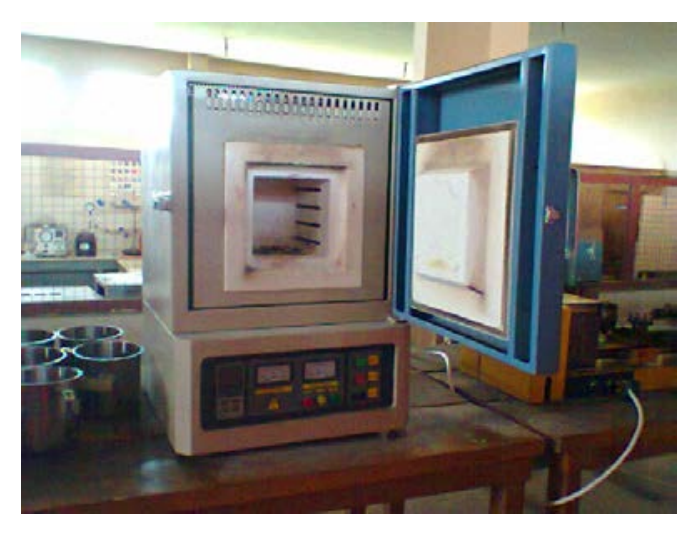

Figure 1: Muffle furnace

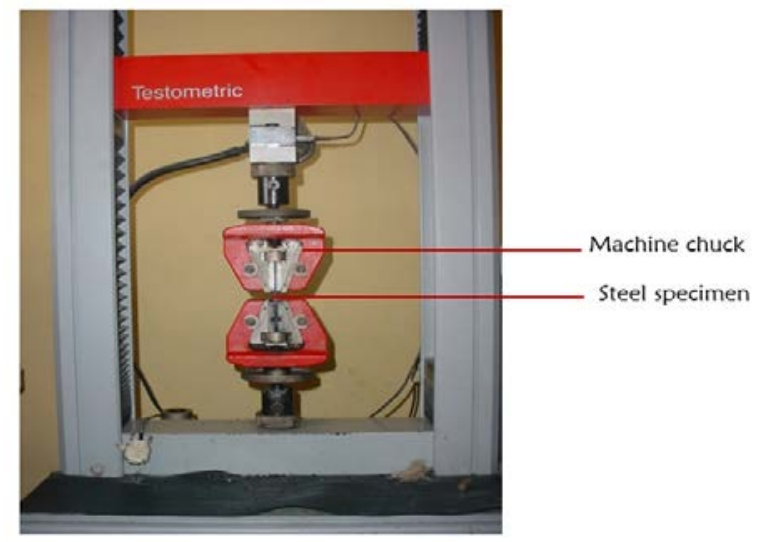

Figure 2: Arrangement of the specimen on the machine chuck

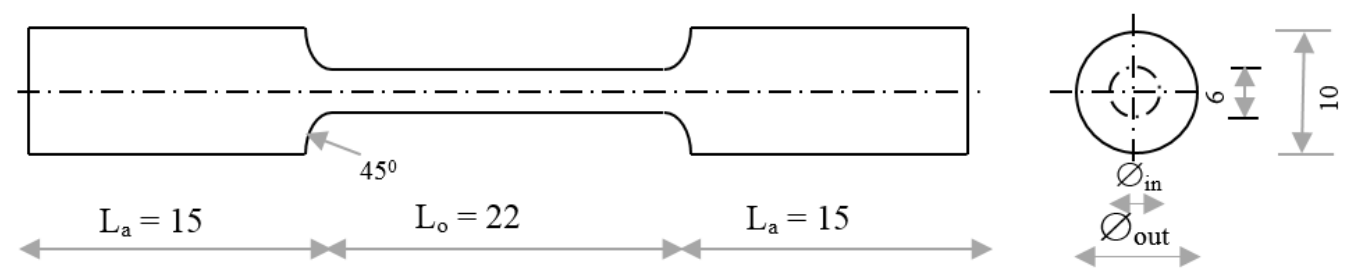

where;

Figure 3: Tensile sample

$\varnothing_{\text {out }}=$ Diameter of gripping heads

$\varnothing_{\text {in }}=$ Diameter of the gauge length

$\mathrm{L}_{\mathrm{a}}=$ Minimum gripping length.

Lo = Gauge length 
The diameter of the test section for the various samples were measured, using Vernier calliper. These was repeated on 4 times on similar prepared samples after which an average value was calculated for further analysis. The percentage reduction, the percentage elongation, yield stress and ultimate tensile strength was obtained thus:

$$
\begin{aligned}
& \text { Cross Sectional Area }=\frac{\pi d^{2}}{4} \\
& \text { Yield Stress }=\frac{\text { Yield load }}{\text { Cross Sectional Area }} \\
& \text { Tensile Stress }=\frac{\text { Maximumload }}{\text { Cross Sectional Area }}
\end{aligned}
$$

\subsection{Hardness Test}

The hardness of a material is resistance to penetration under a localized pressure or resistance to abrasion. Hardness tests provide an accurate, rapid and economical way of determining the resistance of materials to deformation. The Indentec Tech Universal Hardness Testing Machine shown in Figure 4 was used to carry out the hardness test. The type of hardness test was Diamond Rockwell. The minor load of the machine is $10 \mathrm{~kg}$ and the major load is $60 \mathrm{~kg}$, while the indentor is a diamond cone $\left(120^{\circ}\right)$. A load is applied by pressing the indenter at right angle to the surface being tested. The hardness of the material depends on the resistance which exerts during a small amount of plastic or yielding. The resistance depends on elasticity, viscosity, friction and the intensity and distribution of plastic strain produced by a given tool during indentation. The specimen as shown in Figure 5 was place securely upon the anvil, elevated so that it can come in contact with the penetration of the diamond cone indentor. The indention number will display on the digital screen for readings on the scale, which is the indention number of the material. The procedure was repeated 4 times on each sample and the average value was calculated for further analysis.

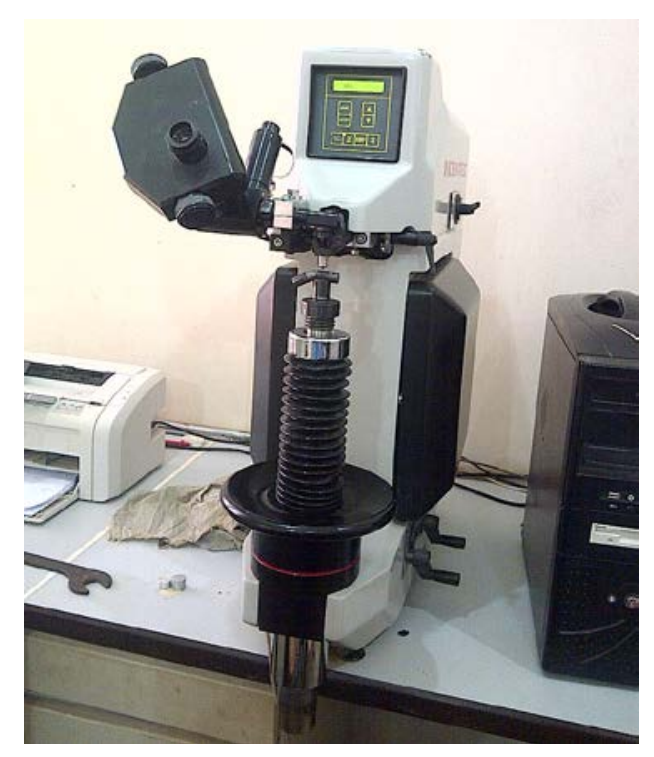

Figure 4: Indentec Tech Universal Testing Machine (Model Number, 900-331D, UNILORIN, NIG.)

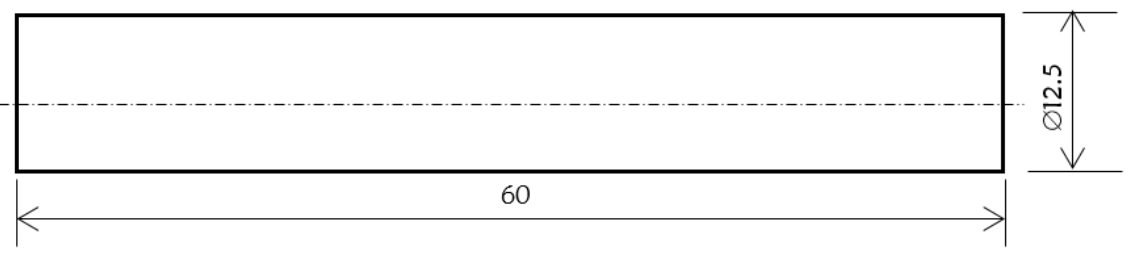

Figure 5: Hardness sample 


\subsection{Impact Test}

Impact test signifies the toughness of a material, i.e., the ability of material to absorb energy during plastic deformation. Static tension tests of un-notched specimens do not always reveal the susceptibility of a metal to brittle fracture. This important factor is determined by impact test shown in Figure 6. Toughness takes into account both the strength and ductility of the material. Several engineering materials have to withstand impact or suddenly applied loads while in service. Impact strengths are generally lower as compared to strengths achieved under slowly applied loads, of all the types of impact test, the notch bar tests are most extensively used. Impact test measures the energy necessary to fracture a standard notch bar by applying an impulse load. The test measures the notch toughness of the material under shock loading.

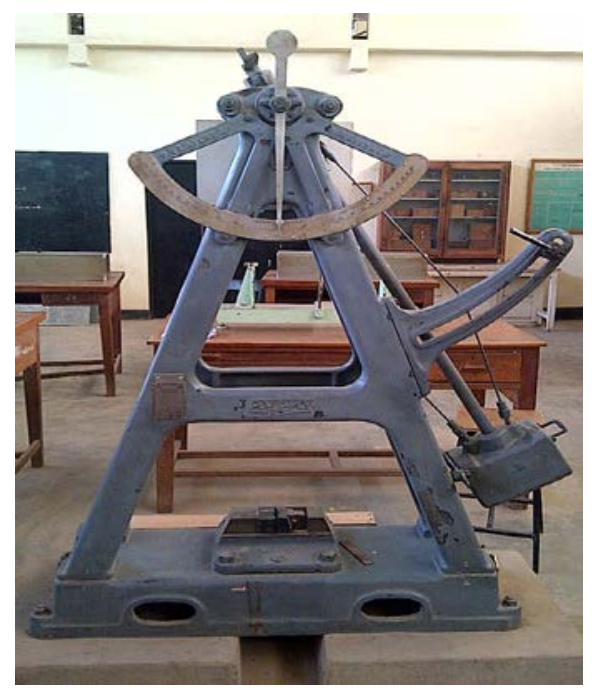

Figure 6: Izod Impact Machine

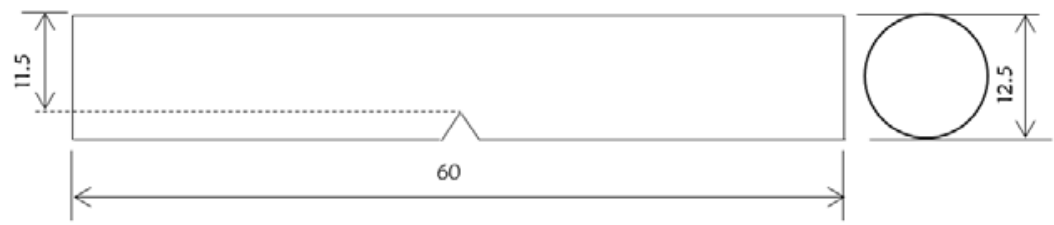

Figure 7: Impact test sample with notch

The test sample was shown in Figure 7 which was first notched to $1 \mathrm{~mm}$. The striking hammer (pendulum) was in safe test position. The weight of the hammer is 162.7 Joules. The specimen was firmly held in the impact testing machine vice in such a way that the notch face the hammer and is half inside and half above the top surface of the vice. The striking hammer is place at its top most striking position and was locked at that position. The gauge of the machine was brought to zero. The hammer was released which fall under gravity and break the specimen as its swing. At its topmost height after breaking the specimen, the indicator stops moving, while the pendulum falls back. The indicator at that topmost final position was noted. The hammer was brought back to its idle position. The process was repeated for the other samples.

\section{MICROSTRUCTURAL EXAMINATION}

Small portions were cut out from the $60 \mathrm{~mm}$ long specimens to produce a surface which appeared scratch free when viewed with the aid of the microscope. This surface was first grind using hand file and later polished to remove the marks left by grinding. The polishing process caused a very thin layer of amorphous metal to be burnished over the surfaces of the specimens, thus hiding the crystal structure.

The specimen was etched with Nital to reveal the crystal structure. This etching reagent dissolved the 'flowed' or amorphous layer of metal. The microstructural examinations of the etched surfaces of the specimens were viewed under a metallurgical microscope as shown in Figure 8. 


\section{RESULTS AND DISCUSSIONS}

The result of the physical properties of the blends were given in Table 2 while Figure 9 and Figure 10 show the plot of load/extension for blend $A$ and $B$ respectively. Tables 3, 4 and 5 show the Percentage elongation/reduction, yield/tensile stress; hardiness value and impact energy respectively. Figure 11 and Figure 12 show the microstructure of the steel samples quenched in the blend to reveal the grain structural and their arrangement.

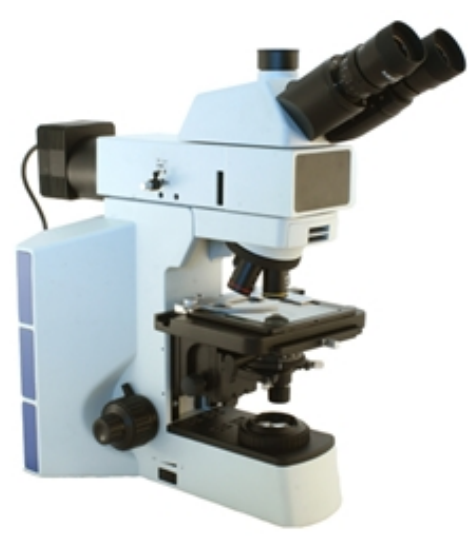

Figure 8: Metallurgical Microscope

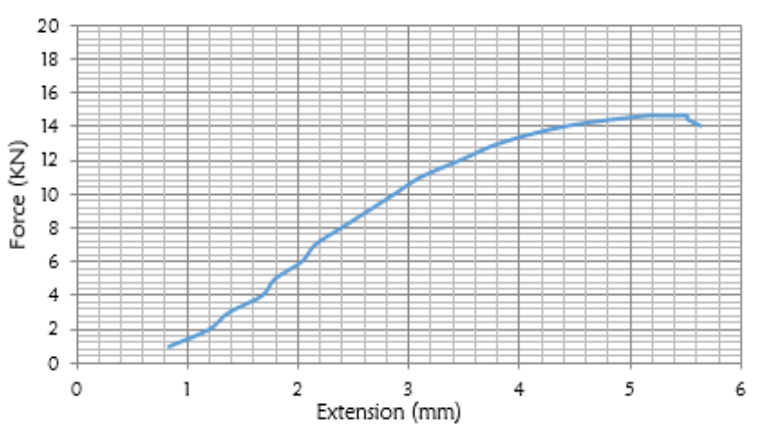

Figure 9: Graph of Load against extension for BLEND A

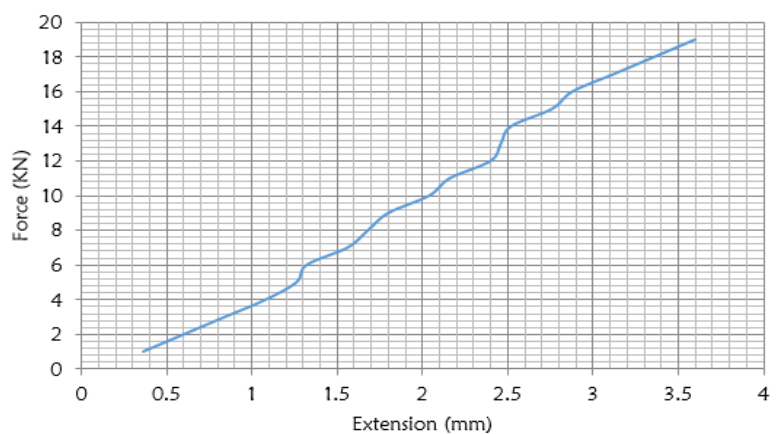

Figure 10: Graph of load against extension for BLEND B

Table 2: Physical properties of the blends

\begin{tabular}{cccccc}
\hline S/N & Blends & Viscosity $(\mathrm{cp})$ & Flash Point $\left({ }^{\circ} \mathrm{C}\right)$ & Acidic Value & lodine Value (\%) \\
\hline 1 & BLEND A & 39.75 & 270 & 14.59 & 2.28 \\
2 & BLEND B & 58.25 & 300 & 25.81 & 2.17 \\
\hline
\end{tabular}

Table 3: Percentage Elongation/Reduction, Yield/Tensile stress of the samples

\begin{tabular}{ccccccc}
\hline S/N & Sample & Diameter $(\mathrm{mm})$ & \% Elongation & \% Reduction & Yield Stress & $\begin{array}{c}\text { Tensile Stress } \\
\left(\mathrm{N}-\mathrm{mm}^{2}\right)\end{array}$ \\
\hline 1 & BLEND A & 4.9 & 7 & 20 & - & 0.77 \\
2 & BLEND B & 4.9 & - & - & - & 1.06 \\
\hline
\end{tabular}

Table 4: Hardness value of samples

\begin{tabular}{ccc}
\hline $\mathrm{S} / \mathrm{N}$ & Samples & Average Hardness (HRA) \\
\hline 1 & BLEND A & 45.7 \\
2 & BLEND B & 54.3 \\
\hline
\end{tabular}


Table 5: Impact energy of the samples

\begin{tabular}{ccccc}
\hline $\mathrm{S} / \mathrm{N}$ & Sample & Diameter $(\mathrm{mm})$ & Notch & Energy $(\mathrm{J})$ \\
\hline 1 & BLEND A & 12.5 & 11.5 & 62.34 \\
2 & BLEND B & 12.5 & 11.5 & 73.21 \\
\hline
\end{tabular}

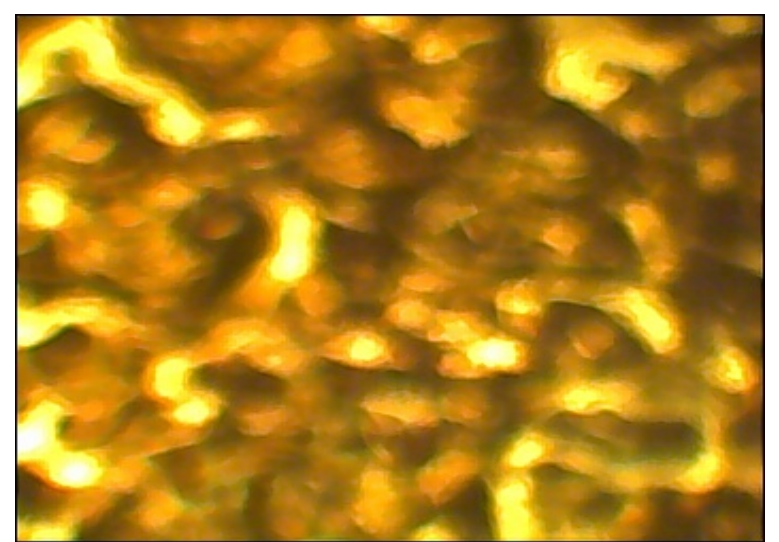

Figure 11: Microstructure of the sample quenched in $500 \mathrm{ml}$ of cottonseed oil and $500 \mathrm{ml}$ of neem seed oil (X400)

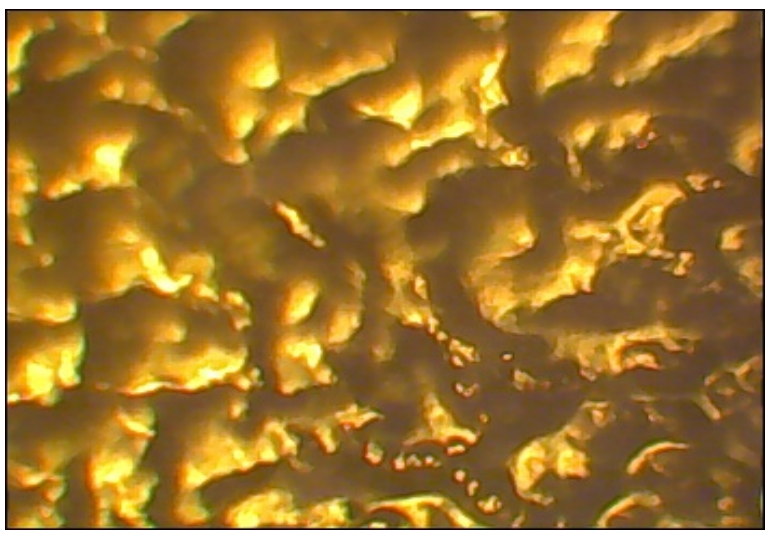

Figure 12: Microstructure of the sample quenched in 250 $\mathrm{ml}$ of cottonseed oil, $250 \mathrm{ml}$ of neem seed oil, $250 \mathrm{ml}$ of Palm kernel oil and $250 \mathrm{ml}$ of shea butter oil (X400)

From the result obtained, Blend $A$ has a lower viscosity, acidic value and flash point compare to Blend $B$, while Blend $A$ has a higher iodine value than Blend $B$. The viscosity of Blend $A$ and Blend $B$ is 39.75 and 58.25 centipoise respectively, the acidic value of Blend $A$ and Blend $B$ is 14.59 and $25.81 \mathrm{mg} / \mathrm{g}$ respectively. The flash point for Blend $A$ and $B$ lend $B$ is tested to be 270 and $300^{\circ} \mathrm{C}$, Blend $A$ and Blend $B$ possesses an iodine value of 2.28 and $2.17 \%$ respectively. The graph of load against extension shows that Blend $A$ produces a strong material which is not ductile while Blend $B$ produces a brittle material. It was also noticed that there was a little strain with the increase in stress. With Blend A fracture occurs at $14 \mathrm{KN}$ while with Blend $\mathrm{B}$, there was no fracture under $20 \mathrm{KN}$ load which is the maximum load for the tensometer used. The result shows that the tensile stresses produced with Blend $A$ and Blend $B$ was 0.77 and $1.06 \mathrm{~N}-\mathrm{mm}^{2}$ respectively while the percentage elongation and reduction for sample with $B$ lend $A$ is 7 and $20 \%$ respectively.

The hardness value obtained for sample with Blend $A$ is lower than that of Blend $B$, this means that the medium carbon steel quenched in $250 \mathrm{ml}$ each of cottonseed oil, neem seed oil, palm kernel oil and shea butter oil has high hardness than medium carbon steel quenched in $500 \mathrm{ml}$ of cottonseed oil and neem seed oil. The hardness value obtained with Blend A is 45.7 HRA while that with Blend B is 54.3HRA. Sample quenched with Blend A shows high impact strength than of Blend $B$. The impact strength of sample quenched with Blend $A$ is 62.4 Joules while that quenched with Blend B is 41.4 Joules.

\section{CONCLUSIONS}

1. It was established that vegetable oils can be used as quenching medium for medium carbon steel since the mechanical properties of the samples quenched using the blending of different oil indicates an improved properties which depends on different combination and mixing ratios

2. Samples quenched in the blend containing each of the oil i.e. Blend B exhibit high tensile strength, hardness and impact energy value compared to the samples quenched in the blend containing only two of oil. This may be due to its high viscosity, acidic and low iodine value, and possibly due to the formation of martensitic structure after quenching.

3. Blend $A$ improves the ductility of the steel samples because it produces lower cooling rate compared with Blend B. Therefore, Blend A would be a viable quenching medium in an areas where improved elongation of the sample is very critical 


\section{REFERENCE}

Adeyemi M.B and Adebayo S.M (2009). Vegetable oils as quenchants for hardening medium carbon steel. Journal of Applied Science and Technology, 14 (1-2), 74-78.

Bell, T. and Staines, A. M. (1983). Heat Treatment Techniques Applied in Manufacturing of Tools and Dies Require for the production of Engineering spare parts. United Nations Industrial Development Organization; Core Industries Group Meeting on the manufacture of Cast/Forged parts, Cairo, Egypt.

Boyer, H. E. (1984). Practical Heat Treating, 1st ed., American

Buczek, A. and Telejko, T. (2004). Inverse determination of boundary condition during boiling water heat transfer in quenching operation. Journal materials Processing Technology, 155-156; 1324-1329

Chaves, J.C., The effect of surface condition and High Temperature oxidation on Quenchinh Performance of 4140 steel in Mineral oil, in Manufacturing Engineering 2001, Worcester Polytechnic Institute: Worcester. 8,9,29

Feng, C. and Tahir I.K. (2008). The effect of quenching medium on the wear resistance of a Ti-6Al-4V alloy. Journal of Material Science, 43, 788-792

Fernandes, P. and Prabhu, K.N. (2008). Comparative study of heat transfer and wetting behavior of conventional and bioquenchants for industrial heat treatment. International Journal of Heat and Mass Transfer. 51:526-538.

George E Totten, D Scott MacKenzie (2003). Handbook of aluminum: vol. 1: physical metallurgy and processes, 1, CRC Press.

Goryushin, V. V Istomin, N. N. Ksenofontov, A.G. Marsel, A.V. Yu Shevchenko, S (1991). Metal Science and Heat Treatment, 41 (1-2, 3-7).

Metals Handbook Desk Edition, ASM International, Materials Park, 1989.

Incropera, F. P., and DeWitt, D. P. (1996). Fundamentals of Heat and Mass transfer, Wiley, New.

Joseph Babalola Agboola*, Oladiran Kamardeen Abubakre, Edeki Mudiare and Michael Bolaji Adeyemi (2016); Performance Assessment of Vegetable Oil and Mineral Oil Blends during Heat Treatment of Medium Carbon Steel; Int. J. Microstructure and Materials Properties, Vol. 11, Nos. 3/4

Kobasko, N.I. Carvalho de souza, E, Canale L.C.F. Totten G.E. (2010). Vegetable oil quenchants: Calculation and Comparison of the cooling properties of a series of vegetable oils, journal of Mechanical Engineering Mills, A. F., Heat Transfer, Prentice Hall.

Ndaliman, M.B. (2006). An assessment of mechanical properties of medium carbon steel under different quenching media. AU J.T. 10(2), 100-104.

Odusote, J. K. Ajiboye, T. K. and Abdulkarim B. (2012). Evaluation of Mechanical Engineering properties of Medium Carbon Steel quenched in water and oil AU J.T. 15 (14), 218-224

Pranesh Rao, K.M. and Prabhu, K.N. (2015) 'Determination of wetting behavior, spread activation energy, and quench severity of bioquenchants', Met. Mat. Trans. B, Vol. 38, pp.631-640.

Rajan, T.V.; Sharma, C.P.; and Sharma, A. (1998). Heat Treatment - Principles and Techniques. Prentice-Hall of India Private Limited, New Delhi.

Smith, W.F. and Hashemi, J. (2006). Foundations of materials science and Engineering", 4thEdition; McGraw's- Hill Book. 28-36.

Singh, V. (2012) 'Assessment of wetting kinematics and cooling performance of select vegetable oils and mineralvegetable oil blend quench media', Materials Science Forum, Vols. 830-831, pp.160-163.

Simencio-Otero, R.L.; Viscaino, J. M., Totten, G. E.; Meekisho, L.; Canale, L. C. F. 29th Heat Treating Society Conference and Exposition, Columbus, OH, October 24-26, 2017.

Thomas G. Diggers, Samuel J. Rosenberg and Glenn W. Geil (1966). Heat treatment and properties of Iron and Steel. 10-19

Totten, G. E., Bates, C. E., and Clinton, N. A. Handbook of Quenchants and Quenching Technology, Materials Park, $\mathrm{OH}$ : ASM International, 1993

Totten, G.E., Howes, Maurice A.H. (1997). Steel Heat Treatment Handbook. W.H Cuberly, Ramon Bakerjian Tools and Manufacturing Engineers Handbook desk edition 